\title{
Crianças surdas e experiências com a palavra escrita
}

\author{
Rosane Aparecida Favoreto da Silva ${ }^{1}$ \\ ORCID: 0000-0002-5479-290X \\ Alessandra Gotuzo Seabra² \\ ORCID: 0000-0002-8373-7897
}

\section{Resumo}

Este artigo apresenta parte de uma investigação sobre o processo de apropriação da língua portuguesa escrita por crianças surdas, sinalizantes de Língua Brasileira de Sinais (Libras), e busca descrever os seus dizeres e analisar as produções induzidas durante a pesquisa. Trata-se de pesquisa qualitativa, descritiva e de cunho exploratório. Participaram seis colaboradores que cursavam a Educação Infantil e os anos iniciais do Ensino Fundamental em uma escola de surdos. Foram utilizadas entrevistas e atividades realizadas a partir da contação de uma história em Libras. Nessas atividades, as crianças escreveram palavras, textos, completaram histórias, criaram personagens e fizeram desenhos. As entrevistas, realizadas em Libras, foram gravadas em vídeo, traduzidas e textualizadas na língua portuguesa escrita. Na análise dos dados, constatou-se que não há distinção inicial entre o processo de apropriação da língua portuguesa das crianças surdas em relação àquelas que são ouvintes, conforme relatado na literatura; entretanto, há diferenciação em relação ao momento em que as crianças ouvintes começam a relacionar o som com a grafia, caracterizando o "ponto de virada" para o entendimento do mecanismo da escrita. Problematiza-se o que pode ser tomado como o "ponto de virada" para as crianças surdas na apreensão do funcionamento da escrita. Verificou-se que elas utilizam pistas visuais e fazem conjecturas para a escrita, que podem estar relacionadas à consciência visual. Esse "ponto de virada" pode ser favorecido por um letramento bilíngue que envolva elementos como escrita de sinais, escrita diferida e escrita bilíngue, a partir de bases diferentes daquelas utilizadas com as crianças ouvintes.

\section{Palavras-chave}

Educação de surdos - Educação bilíngue de surdos - Alfabetização e letramento - Língua portuguesa escrita.

1- Secretaria de Estado da Educação do Paraná, Curitiba, PR, Brasil. Contato: rofavoreto@yahoo.com.br

2- Universidade Presbiteriana Mackenzie, São Paulo, SP, Brasil. Contato: alessandra.seabra@mackenzie.br 


\section{Deaf children and experiences with the written word}

\section{Abstract}

This article presents part of an investigation into the process of appropriation of the written Portuguese language by deaf children, signers of Brazilian Sign Language (Lingua Brasileira de Sinais [Libras]). It seeks to describe their sayings and analyze the induced productions during the research. Six collaborators participated who attended Kindergarten and early elementary school years in a deaf school. This is qualitative, descriptive and exploratory research. Interviews and activities based on telling a story in Libras were used. In these activities, the children wrote words and texts, completed stories, developed characters, and drew pictures. The interviews, conducted in Libras, were videotaped, translated and textualized in written Portuguese. Data analysis found no initial distinction between the Portuguese language appropriation process of deaf children and those who are hearing, as reported in the literature. However, there is a difference when hearing children relate sound to spelling, characterizing the "turning point" for understanding the writing mechanism. We question what can be taken as the "turning point" for deaf children in the apprehension of writing functioning. It has been found that they use visual clues and make conjectures for writing, which may be related to visual awareness. This "turning point" can be favored by a bilingual literacy that involves signwriting, deferred writing and bilingual writing from different bases than those used with hearing children.

\section{Keywords}

Deaf education - Bilingual education for the deaf-Literacy - Written Portuguese language.

\section{Introdução}

A apropriação da escrita da língua portuguesa pelas pessoas surdas ainda é tema de muitos debates e inquietações, tanto no meio acadêmico como nos espaços de escolarização. Apesar disso, verificou-se que é pequeno o número de investigações cujo objeto é a apropriação da língua portuguesa escrita por crianças surdas no início de seu percurso escolar ${ }^{3}$. Este artigo apresenta parte do resultado de uma pesquisa (FAVORETO DA SILVA, 2020) que teve como objetivo responder a seguinte questão: como crianças surdas sinalizantes de Libras, no início da escolaridade, fazem registros e o que elas dizem sobre a escrita da língua portuguesa?

Como pressuposto para a investigação, destaca-se a educação bilíngue de surdos realizada em Língua Brasileira de Sinais (Libras) e em Língua Portuguesa -, na perspectiva em que a Libras é a primeira língua das pessoas surdas, que possibilita a constituição de

3- Busca realizada nos sites do Banco de Teses e Dissertações da Capes e do Periódicos da Capes contendo as seguintes palavras-chave e respectivos operadores: Surd* AND “Língua Portuguesa” AND escrita, no período de 10 anos (2009-2018). 
conhecimento de mundo e a construção de sentido dos textos produzidos, tendo um papel fundamental na aquisição da leitura e da escrita (KARNOPP; PEREIRA, 2015).

Sobre a língua portuguesa na educação de surdos, considera-se que ela é a segunda língua das pessoas surdas brasileiras que usam a língua de sinais para a comunicação, sendo uma língua que apresenta estrutura morfossintática distinta da Libras, fatores que interferem no processo de escrita dos surdos. Mas há um terceiro aspecto que se evidencia como parte central desta pesquisa: a língua portuguesa não é a língua que viabiliza a organização e o desenvolvimento dos processos do pensamento dos surdos, lugar ocupado pela língua de sinais. Desta forma, cabe a reflexão: "é possivel conhecer o objeto da linguagem (do pensamento) fora da linguagem (do pensamento)?" (CARDOSO, 2003, p. 11). Ou seja, na escrita da língua portuguesa é comum que a pessoa surda não utilize o referente de um conceito expressado na língua oral, tendo em vista o impedimento do surdo de ouvir a palavra falada. 0 referente pode ser conhecido, mas ele não é associado ao uso oral da palavra e, logo, à escrita dessa mesma palavra.

As diferenças linguísticas e culturais dos alunos surdos em relação aos alunos ouvintes se evidenciam nas situações de aprendizagem no contexto escolar, sendo importante buscar compreender como esses alunos surdos concebem o mundo por meio das experiências visuais. Conhecer o que pensam as crianças surdas sobre a escrita contribui para a compreensão do processo de escolarização e a criação de fontes originais que podem favorecer novas pesquisas na área.

\section{Escrita: a experiência da palavra como (in)completude da língua}

A escrita, como uma invenção cultural, tem sido caracterizada no âmbito educacional "[...] ora como um código, ora como a invenção de um sistema de representação, ora ainda como a invenção de um sistema notacional" (SOARES, 2016, p. 46, grifo do autor). Para essa autora, a escrita é um sistema de representação porque a criança, em seu processo de compreensão da língua escrita - que se inicia antes da instrução formal -, "reconstrói" o processo de invenção do ato de escrever como representação. Mas, ao compreender o que a escrita representa (a cadeia sonora da fala, não seu conteúdo semântico), a criança precisa aprender também a notação com que, arbitrariamente e convencionalmente, são representados os sons da fala (os grafemas e suas relações com os fonemas, bem como a posição desses elementos no sistema), dessa forma, caracterizando-se também como um sistema notacional.

Compreender o que e como as letras notam e representam faz parte de um processo fundamental para que a criança aprenda a escrever. Porém, para Faraco (2012), a escrita não se esgota na notação; aprender as práticas escritas exige um mergulhar em tradições discursivas, uma vez que diz respeito não somente aos sistemas de transcrição gráfica da linguagem verbal, mas fundamentalmente à mobilização de vários saberes, como os gramaticais, lexicais, sociais, textuais etc., e de práticas cognitivas e socioculturais que não começam nem terminam com o domínio da alfabetização. A alfabetização é apenas o momento específico de aprendizado do sistema de notações gráficas. 
A ideia de que a escrita não é um código de transcrição da língua oral - mas, sim, um sistema de representação da realidade - e que o processo de alfabetização é o domínio progressivo desse sistema - que se inicia antes da criança se escolarizar -, e não a aquisição de habilidade mecânica, está entre algumas das similaridades das abordagens sobre a escrita a partir de autores como Vygotsky, Luria e Ferreiro, segundo Oliveira (2000).

Vygotsky (1984), assim como Ferreiro (2001), postula que a criança, imersa na sociedade letrada, está exposta às características, funções e modalidades de utilização da língua escrita e aos seus diferentes usos, que vão lhe permitir desenvolver pressupostos sobre esse objeto cultural. A criança adquire noções sobre a escrita antes de se escolarizar, as quais serão sistematizadas em situações formais de aprendizagem.

Mesmo fazendo parte de uma sociedade letrada a criança não se torna alfabetizada sozinha. Diferentemente da língua falada, que a criança pode desenvolver por si mesma, a aprendizagem da escrita depende de um ensino formal, pois a aprendizagem desse objeto cultural complexo depende de processos deliberados de ensino, aponta Vygotsky (1984). Desta forma, o autor se preocupa com uma intervenção pedagógica intencional para que a criança aprenda a ler e escrever, pelo fato de que o mero contato com o objeto não garante a aprendizagem, sendo necessária a mediação de outras pessoas - nesse caso, o professor para o desenvolvimento do processo da apropriação da escrita. Luria (1988, p. 144) postula que, diferentemente de outras funções psicológicas, “[...] a escrita pode ser definida como uma função que se realiza, culturalmente, por mediação”, funcionando como instrumento que possibilita a ampliação da capacidade humana de registro, transmissão e recuperação de ideias, conceitos, informações.

$\mathrm{Na}$ fase escolar, entre especificidades que envolvem a apropriação da escrita alfabética, está o fato de que crianças surdas mobilizam habilidades diferentes daquelas utilizadas pelas ouvintes; a correspondência entre a pauta sonora e a escrita, por exemplo, é essencial para as crianças ouvintes (FERREIR0; TEBEROSKY, 1999), mas não é utilizada por crianças surdas (ou é usada precariamente no caso de crianças com resíduos auditivos e implantes). Essa habilidade tem sido denominada por pesquisadores de consciência fonológica (CAPOVILLA, 2000; MORAIS, 2012), sendo entendida como uma habilidade metalinguística, portanto, consciente e voluntária, que corresponde à capacidade de analisar voluntariamente a fala, segmentá-la em partes e manipular esses segmentos (CAPOVILLA, 2000).

Assim como Vygotsky (1984) e Luria (1988) se interessaram pelo trajeto percorrido pela criança durante o seu processo de desenvolvimento da escrita, Ferreiro (2001) também buscou investigar e demonstrar que as crianças pensam a propósito da escrita e que seu pensamento tem coerência. Nessa perspectiva, é possivel dizer que as crianças formulam hipóteses e são criadoras dos instrumentos de seu conhecimento, assim como acontece com aquelas que são surdas, com a diferença de que, nesse caso, esse processo não se efetiva pela rota auditiva. Luria (1988) aponta que a criança percorre um caminho gradual de diferenciação dos símbolos, constatando em suas análises que ela realiza inúmeras tentativas para elaborar métodos primitivos antes de compreender o sentido e o mecanismo da escrita, ressaltando que é o ato que produz a compreensão do uso dos signos e não o contrário. Desta forma, considerando que o caminho percorrido pelos surdos para a 
apropriação da língua portuguesa escrita não é centrado na relação da escrita com a oralidade, de acordo com os pressupostos vygotskyanos, buscou-se investigar e registrar o que as crianças surdas disseram sobre a escrita, descrevendo como utilizaram as letras e as palavras, e o que elas representavam naquele momento.

\section{Alfabetização e letramento de surdos: o oferecer a linguagem}

Alfabetização e letramento são terminologias de uso atrelado ao contexto do ensino e da apropriação da língua escrita, mesmo que lhes sejam atribuídos vários significados, às vezes discordantes, mas relacionados entre si. Atualmente, a palavra letramento é utilizada também em outros contextos, mas seu surgimento ocorreu no campo educacional. Aqui, na esteira de pesquisadores como Rojo (2009), Street (2010) e Soares (2014), adota-se como pressuposto que o letramento é um conjunto de práticas sociais relacionadas ao que as pessoas fazem e como usam a leitura e a escrita em diferentes contextos sociais, culturais e históricos, levando em conta como essas habilidades se relacionam com valores e necessidades em uma multiplicidade de práticas letradas. Nesse sentido, problematiza-se o letramento na educação de surdos, diante das especificidades do jeito surdo de ser e das questões linguísticas e culturais que envolvem esses sujeitos.

0 letramento e a apropriação da língua escrita pelos sujeitos surdos têm sido motivo de preocupação para vários pesquisadores da área - Gesueli $(1998,2015)$, Lebedeff $(2010$, 2017), Karnopp e Pereira (2015), Formagio e Lacerda (2016), entre outros -, provocando questionamentos sobre estratégias e métodos a serem utilizados no processo de construção da escrita do português, tendo em vista que a oralidade não deve se constituir como pressuposto para a alfabetização e o letramento das pessoas surdas. Para Gesueli (2015), na educação de surdos, o aspecto visual constitui fator fundamental para a apropriação da língua portuguesa escrita, sendo necessário haver um distanciamento da noção de escrita como representativa da oralidade, afastando-se de uma concepção grafocêntrica da escrita e considerando as ações que se fazem com e sobre a língua como prática discursiva. Nessa perspectiva, o letramento visual se apresenta como um fator relevante no processo de escolarização das pessoas surdas, ressaltam Gesueli e Moura (2006).

Letramento visual, na esteira de Lebedeff (2010), é uma área de estudo que é abordada a partir de diversas disciplinas visando estudar os processos físicos envolvidos na percepção visual, o uso das tecnologias para representar a imagem visual e o desenvolvimento de estratégias para compreender o que é visto. Nesta direção, e em conformidade com Gesueli (1998, 2015), Lebedeff (2010) aponta que a presença da língua de sinais, juntamente com a produção de uma cultura que também é visual e prescinde do som, evidencia a característica visual da condição de surdez. Na educação de surdos, as experiências que privilegiam a visualidade fazem parte do modo de vida e do jeito surdo de ser, compartilhadas na comunidade surda, possibilitam o acesso a estratégias visuais e compreensão de mundo com base em práticas que tenham eventos de letramento visual como ponto de partida. Ao ressaltar que os surdos utilizam estratégias diferentes das utilizadas pelos ouvintes para o ensino da língua escrita, sugerem-se práticas que contemplem o letramento visual, que "precisa ser compreendido, também, a partir de práticas sociais e culturais de leitura e compreensão de imagens” (LEBEDEFF, 2010, p. 179). 
As imagens são representações porque são criadas e produzidas pelos seres humanos nas sociedades em que vivem, tornando-se necessária a sistematização e instrumentalização do letramento visual para uma maior compreensão das informações e experiências pelos sujeitos, proporcionando as habilidades para que possam ler as imagens e ter um maior refinamento da leitura (DONDIS, 2015; SANTAELLA, 2012). Nesse contexto, Santaella (2012) ressalta a necessidade de a escola dar a importância cognitiva que a imagem merece nos processos de ensino e aprendizagem, pois é comum que docentes ainda estejam presos à ideia de que o texto verbal é o grande transmissor de conhecimentos, não considerando a alfabetização visual de seus alunos.

Taveira (2014), em sua tese de doutorado, buscou preencher as lacunas apontadas por Lebedeff (2010), investigando quais seriam as práticas pedagógicas decorrentes das necessidades discursivas da experiência visual da surdez e a quais eventos de letramento se referem esses discursos. Taveira (2014) constatou o apelo imagético e o uso de artefatos visuais presentes na prática pedagógica de professores surdos, que acrescentavam outros olhares ao letramento, à leitura, à escrita e à produção literária, evidenciando a questão visual pela necessidade de ler a imagem como texto, bem como pelas pistas visuais que apresentam. A autora observou, na sala de aula de docentes surdos, a presença de equipamentos para registro de imagens e organização do espaço, os quais ela denomina de extensões do corpo, sendo eles: câmera fotográfica, filmadoras, notebooks, computadores, celulares, tablets e internet.

Mesmo que docentes surdos e ouvintes bilíngues utilizem recursos e estratégias visuais, como vídeos didáticos e educativos em língua de sinais, vídeos para divulgação, fotografias com finalidade informativa, entre outros, Taveira (2014) verifica que não há uma busca pelo letramento ou alfabetismo visual, mas há indícios e intuições sobre como atuar com os alunos surdos utilizando tais recursos e um jeito de ensinar que ainda está sendo construído, com produções desordenadas, não catalogadas, mesmo com a interação entre esses docentes nas redes sociais e outros espaços. A experiência visual não deve se constituir somente por intuições nas estratégias utilizadas por docentes na educação de surdos, ela deveria ocupar espaço central na organização do ensino para essas crianças.

As práticas pedagógicas, somadas aos artefatos tecnológicos, possibilitam ampliar o letramento para o campo da imagem e de outras semioses, e não somente o da escrita. Aponta-se para práticas de letramento visual e uso das tecnologias digitais diante dos recursos multimodais e multissemióticos, fazendo o uso de textos diferidos que podem ser tanto textos escritos como videogravações, conforme salienta Peluso (2018). Figueiredo e Guarinello (2013) sugerem o uso de textos multimodais no letramento de pessoas surdas, multimodalidade que pode envolver vários elementos, como textos escritos, cores, imagens, gráficos, entre outros recursos semióticos. Nesse sentido, na esteira de Rojo (2009), Figueiredo e Guarinello (2013) postulam que a multimodalidade abre possibilidades para o professor incorporar os aspectos visuais às suas práticas com o propósito de garantir interações que possibilitem a inserção dos seus alunos em práticas letradas.

Gesueli e Moura (2006) evidenciam a importância de considerar os aspectos socioculturais do indivíduo surdo, a especificidade da língua de sinais e a função da escrita como decorrente de práticas discursivas, sendo relevante conceber o letramento na 
educação de surdos como um processo multimodal caracterizado pelo uso de mais de um código semiótico, atravessado por múltiplos códigos de significação.

Nesse contexto, este estudo investiga como crianças surdas sinalizantes de Libras, no início da escolaridade, fazem registros e o que elas dizem sobre a escrita da língua portuguesa.

\section{Método}

Os colaboradores da pesquisa foram seis crianças surdas, sinalizantes de Libras, que cursavam a Educação Infantil ou os anos iniciais do Ensino Fundamental em uma escola de surdos localizada no município de Paranaguá, estado do Paraná. As crianças tinham entre três e doze anos de idade. Realizaram-se entrevistas que foram registradas em vídeo, pois a língua usada para a comunicação foi a Libras, uma língua na modalidade visual, gestual e espacial, sinalizada com as mãos e que contém expressões faciais que são gramaticais. Como a Libras é parte do objeto da pesquisa, a necessidade da gravação em vídeo não se restringiu a uma questão metodológica, mas faz parte do conteúdo da própria investigação. Outro aspecto fundamental das entrevistas em vídeo se refere à privacidade e à confidencialidade: a participação dos colaboradores na pesquisa foi autorizada por meio do Termo de Consentimento Livre e Esclarecido e o uso da imagem foi cedido por meio do Termo de Cessão e Uso de Imagem. Mesmo os responsáveis legais pelas crianças tendo optado pelo uso dos seus nomes verdadeiros, neste artigo os seis colaboradores foram identificados como A, B, C, D, E e F.

$\mathrm{Na}$ esteira de Kramer (2002), também se obteve o assentimento da criança em participar da entrevista. Dessa forma, foram cumpridos todos os requisitos previstos na Resolução no 510/2016 do Conselho Nacional de Saúde, que normatiza a ética na pesquisa com seres humanos, e todo o procedimento foi aprovado em parecer da Comissão de Ética da Faculdade de Educação da Universidade de São Paulo nº 082/2017.

A pesquisa caracteriza-se como qualitativa, descritiva e exploratória, com a elaboração e adoção, além das entrevistas, de um conjunto de procedimentos para coletar os dados sobre como e o quê as crianças dizem sobre a escrita. A entrevista foi semiestruturada, aproximando-se de uma conversa, utilizando um roteiro para a condução das ações da pesquisadora, conforme apontado por Lankshear e Knobel (2008), uma vez que se tratava de uma coleta de dados feita junto a crianças pequenas.

Além da entrevista semiestruturada, foi organizado um conjunto de atividades a serem realizadas pelas crianças com a finalidade de coletar os dados escritos e verbais produzidos por elas. De acordo com Luria (1988), para a criança escrever é importante que as coisas representem algum interesse para elas, como as coisas com as quais brincam, ou que os objetos envolvidos tenham um papel instrumental e utilitário para auxílio na obtenção de outro objeto. Desta forma, considerando que o uso de instrumentos como as histórias infantis aproxima o pesquisador e a criança, podendo envolvê-la por meio de propostas lúdicas, o roteiro partiu da contação de uma história infantil em Libras, adaptando o livro Viviana, a rainha do pijama, de Steve Webb, que compõe o acervo de obras complementares do Programa Nacional do Livro e do Material Didático (PNLD). 
A partir da contação da história foi elaborado o roteiro de atividades para que as crianças pudessem escrever palavras e textos, completar histórias, criar personagens e fazer desenhos. Há pesquisas que utilizam métodos semelhantes, como história a completar e desenho com histórias, em trabalhos das pesquisadoras Cruz (2009) e Correa e Bucci (2018), as quais consideram que tais métodos se constituem como estratégias bemsucedidas para a coleta de dados em pesquisas com esse público-alvo.

Quanto aos materiais e às estratégias que fizeram parte desta pesquisa, foram utilizados recursos imagéticos e multimodais, observando-se a motivação e o interesse das crianças surdas na participação das atividades e nas informações disponibilizadas. A contação da história em Libras, por meio de recursos de vídeos, constituiu uma estratégia importante devido a dois fatores: a) teve a função de contar a história, caracterizada como uma textualidade diferida (PELUSO, 2014), mostrando-se como uma ação que pode ser exitosa no letramento de crianças surdas; e b) houve a identificação linguística tendo um surdo adulto como referência.

As produções escritas apresentadas neste texto fazem parte do roteiro de atividades que as crianças realizaram. A escrita de vocabulário está relacionada aos animais que são personagens do livro e outros escolhidos pelas crianças, e na escrita do texto, do gênero carta, elas elaboraram uma resposta ao convite de aniversário da menina Viviana.

As entrevistas foram realizadas em Libras, gravadas em vídeo, traduzidas e transcritas para a língua portuguesa, caracterizando-se como uma tradução interlingual e intermodal, considerando que esse processo envolve duas línguas de modalidades diferentes.

\section{Resultados: a palavra dita}

Mesmo que escrever seja um processo que, em muitos aspectos, difere do ato de falar, é fundamental destacar que a escrita, ao representar a fala, está representando a língua falada oralmente. Desta forma, para Soares (2016), a essência da escrita alfabética é esta conversão de sons em letras, ou seja, o sistema de escrita alfabético foi criado com base na língua oral para representar a fala das pessoas. Nesse contexto é que deve ser problematizado o fato de que o processo de aprendizagem da escrita da língua portuguesa pela pessoa surda se estabelece como o aprendizado do sistema de escrita que representa uma língua cuja modalidade (a oral) não lhe é acessível, ou é pouco acessível. A pesquisa evidencia que as dificuldades para a apropriação da escrita pelos surdos não estão relacionadas somente ao fato de a língua portuguesa se configurar como a segunda língua, mas ao fato de haver um sistema de escrita alfabética cuja constituição e função é pautada na representação da língua oral a ser registrada. Diante disso, é necessário problematizar o que se utiliza como referência nas tentativas de ensinar as pessoas surdas a escrita da língua portuguesa.

Logo, é pertinente refletir sobre o papel do signo linguístico e seu referente no uso da linguagem pelas pessoas surdas. Referência, conforme Cardoso (2003, p. 1) é "a relação entre a linguagem (um dizer) e uma exterioridade (um não dizer), relação necessária para que a linguagem tenha o seu valor e não se encerre em si própria”. 
Por outro lado, segundo Vygotsky (1984), o desenvolvimento da escrita é independente do desenvolvimento da fala e as crianças podem aprender a escrever sem que esta ação esteja vinculada à fala. De acordo com Silva (2008), a criança ouvinte supera a condição abstrata da palavra quando se apropria do significado presente na combinação de sons própria de cada palavra. Porém, a criança surda, sinalizante da língua de sinais, somente o fará pela percepção visual, quando (ou se) se apropriar do significado possibilitado pela combinação de movimentos que compõe cada sinal da Libras, convertendo para o sistema de escrita aa língua alfabética que não mantém relação estrutural com a língua usada pela criança.

Nesse contexto, evidenciaram-se algumas formas de registros pelas crianças surdas, que estão dispostas a seguir, apresentando as produções do vocabulário (a) e dos textos (b) de cada colaborador:

Criança A, Educação Infantil, 3 anos de idade: a) Registrou palavras contendo letras misturadas com números, sendo a maioria das letras aquelas que fazem parte do seu nome. Na maior parte da escrita do vocabulário, realizou desenhos, contornando os objetos representados (a Figura 1 ilustra uma produção da criança). b) Na escrita do texto, desenhou, assim como havia feito no vocabulário, não fazendo distinção entre a produção do texto e a escrita das palavras, mobilizando os mesmos recursos.

Tais produções estão de acordo com a idade para crianças surdas e ouvintes.

Figura 1 - Escrita da criança A ao nomear a imagem da vaca
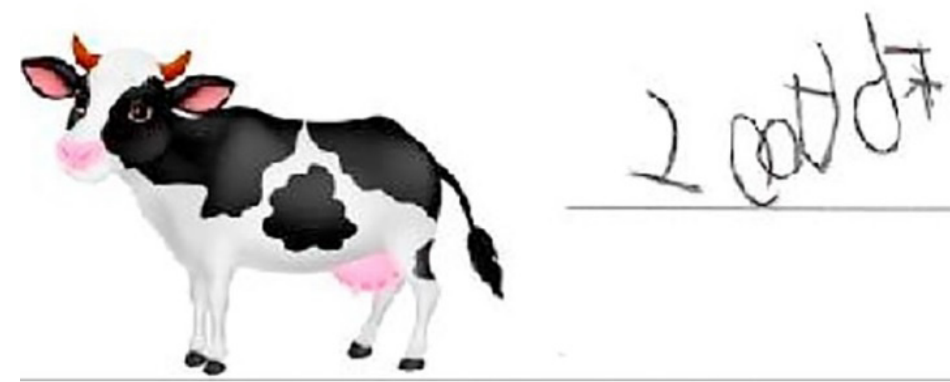

Fonte: Dados da pesquisa.

Criança B, Educação Infantil, 5 anos de idade: a) Registrou palavras utilizando as letras do próprio nome, algumas vezes acrescentando outras letras. As palavras escritas não repetiram a ordenação e a combinação das letras, conforme Figura 2. b) 0 texto foi produzido por meio de rabiscos imitando as formas de letras cursivas, com características pictográficas, registrado de forma diferente do vocabulário. A escrita foi utilizada de forma externa, não se caracterizando como um recurso para a memória.

Essas produções também estão condizentes com a faixa etária das crianças surdas e ouvintes. 
Figura 2 - Escrita do nome de animais, personagens do livro, produzida pela criança B

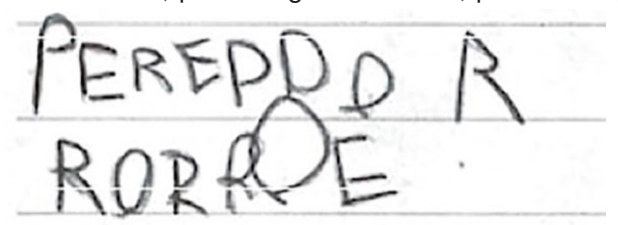

Fonte: Dados da pesquisa.

Criança C, $2^{\circ}$ ano, 9 anos de idade: a) Registrou palavras utilizando aletoriamente várias letras do alfabeto, em caixa alta, sem fazer uso das propriedades do sistema de escrita alfabética. A escrita não foi utilizada como um recurso para memória, a partir do qual a criança poderia se lembrar do que já havia escrito. b) 0 texto foi produzido com letras variadas, sem uso das propriedades da escrita alfabética, conforme realizado na escrita das palavras. Essas produções não conseguiram registrar ideias e conceitos, caracterizando-se como uso do desenho pictográfico, de forma instrumental, para completar as informações da produção textual (Figura 3). Na escrita do vocabulário, não foi identificado o registro de desenhos.

Figura 3 - Texto da carta produzido pela criança $C$

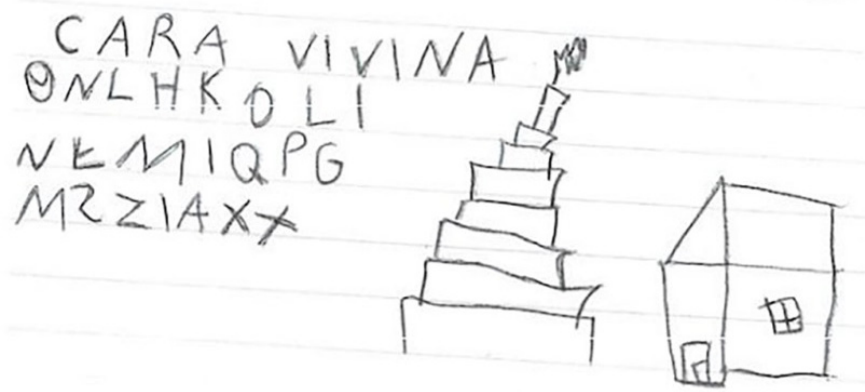

Fonte: Dados da pesquisa

Criança D, $5^{\circ}$ ano, 12 anos de idade: a) Evidenciou o registro de palavras estáveis, com escrita realizada em letra cursiva, mesmo que em fase de aprendizagem de suas formas, conforme Figura 4. b) Texto produzido por meio de rabiscos, imitando as formas de letras cursivas, com elementos parecidos com palavras que eram estáveis para a colaboradora.

Figura 4 - Escrita do nome de um animal, personagem do livro, produzida pela criança D com palavras estáveis

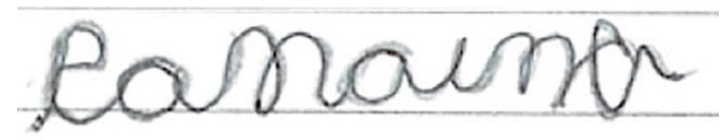

Fonte: Dados da pesquisa 
Criança E, $3^{\circ}$ ano, 8 anos de idade: a) Registrou algumas palavras em letra cursiva, usando propriedades alfabéticas e seguindo pistas visuais para a escrita (Figura 5). b) 0 texto foi produzido com várias letras registradas aleatoriamente em letra cursiva, completando uma ou duas linhas da folha, sem espaçamento entre elas. Produção textual realizada de forma diferente do registro do vocabulário.

Figura 5 - Tentativas, produzidas pela criança E, da escrita da palavra "leão" seguindo pistas visuais

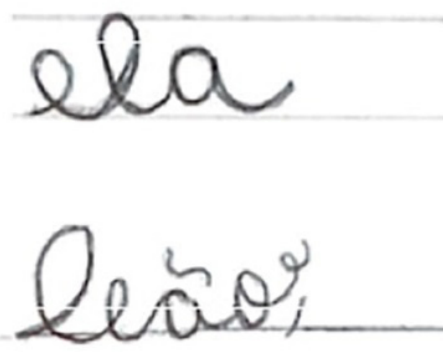

Fonte: Dados da pesquisa.

Criança F, $5^{\circ}$ ano, 11 anos de idade: a) Registrou a escrita de forma simbólica e convencional quando conhecia a palavra a ser registrada, evidenciando o uso da escrita como um instrumento para a memória. Quando não tinha conhecimento da escrita de determinada palavra, usou pistas visuais para registrá-las. b) 0 texto foi produzido com escrita simbólica convencional, registrando ideias e conceitos, entretanto, com características de escrita em segunda língua, como é usual em textos produzidos por pessoas surdas, conforme apresentado na Figura 6. Ou seja, o texto foi registrado com a estrutura linguística de língua de sinais, não contendo os conectivos e a concordância nominal e verbal, tal qual apresentado na sintaxe da língua portuguesa.

Figura 6 - Texto da carta produzida pela criança $F$

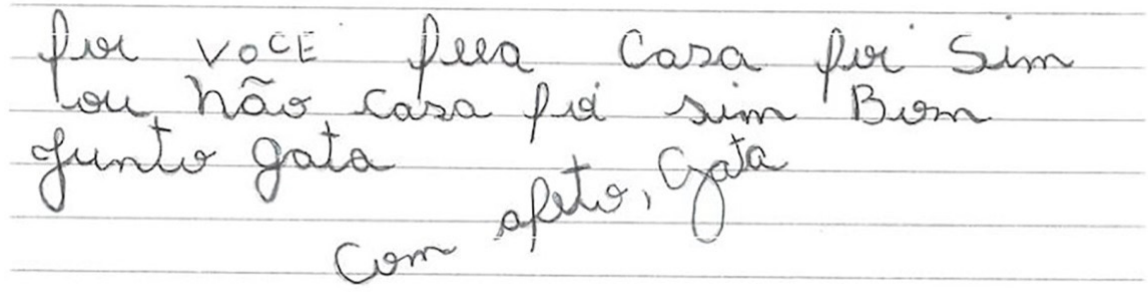

Fonte: Dados da pesquisa.

\section{Discussão e conclusões}

Há muitos aspectos desafiadores em pesquisas que envolvem crianças pequenas, principalmente no que diz respeito à coleta e geração de dados que envolvem produções 
escritas em língua portuguesa. As crianças contavam coisas animadamente em Libras, mas, quando foi solicitado que escrevessem, havia uma reação de estranhamento, de negação ou dúvida, com uma intensidade menor ou maior, dependendo do colaborador.

Ao serem analisadas as produções escritas, ficou evidente que há um ponto crucial, um divisor no processo de desenvolvimento da escrita das crianças surdas em relação às ouvintes, que foi denominado neste trabalho de "ponto de virada". Primeiramente, constatou-se que as crianças surdas, na fase equivalente àquela que Luria (1988) chama de pré-história da escrita, e no início da sua apropriação, registram as palavras e textos da mesma forma que as crianças ouvintes, fazendo o uso da escrita primitiva, de forma que o ato de escrever parece dissociado do objeto, com registro de desenhos pictográficos de maneira autocontida ou instrumental, usando letras e números conhecidos e criando hipóteses sobre a escrita que realizam. Portanto, não há distinção inicial entre o processo de apropriação da língua portuguesa escrita para as crianças ouvintes e surdas, mesmo que essa não seja a língua utilizada pela criança surda como língua de interação e instrução.

Nesta fase do desenvolvimento da escrita, as crianças surdas fizeram o uso da escrita pictográfica; registraram palavras usando as letras de seus nomes, com variações internas e combinações diferentes; realizaram registros de palavras utilizando aletoriamente várias letras do alfabeto, em caixa alta, sem fazer uso das propriedades do sistema de escrita alfabética; e, também, utilizaram palavras estáveis para elas. Tais estratégias são encontradas no processo de desenvolvimento da escrita de crianças ouvintes (FERREIR0; TEBEROSKY, 1999, LURIA, 1988; MORAIS, 2012), entretanto essas formas de escrever passam a se diferenciar em relação às crianças surdas, quando as ouvintes começam a relacionar o som à grafia (FERRREIRO; TEBEROSKY, 1999) e fazem uso da escrita instrumental (VYGOTSKY, 1984). Esse é o momento em que a criança começa a entender o mecanismo da escrita e registra o objeto denotado, caracterizando o "ponto de virada" para as crianças ouvintes, mas não para a criança surda, uma vez que a correspondência entre a fala e a grafia se efetiva pela rota auditiva.

No caso da criança ouvinte, de acordo com Ferreiro e Teberosky (1999), esse momento se origina quando é feita a correspondência da fala com a grafia, dissociando-a de seu significado e segmentando-a, no domínio de uma habilidade metalinguística; ou seja, a consciência fonológica é fundamental para o desenvolvimento da escrita na criança ouvinte. Soares (2016, p. 166, grifo do autor) ressalta que a inserção da criança no mundo da escrita é constituída pela

[...] compreensão da escrita como representação visual dos sons que compõem a cadeia sonora da fala - a escrita como a fala tornada visivel - e da aprendizagem do sistema e das normas de relações entre os fonemas que compõem a palavra falada e os grafemas que os representam.

Nos estudos com crianças ouvintes, para Luria (1988), o ponto de virada evidencia-se no emprego da escrita instrumental, na sua utilização como apoio de funções intelectuais como requisito para o uso do sistema convencional. Da mesma forma, Vygosty (1984) afırma que a criança usa a escrita como simbolismo de segunda ordem ao compreender a criação de sinais escritos como representação dos símbolos falados das palavras, 
entendendo que se pode "desenhar" a fala. Porém, cabe lembrar que os signos mudam, não são estáticos.

\begin{abstract}
Enquanto símbolos de segunda ordem, os símbolos escritos funcionam como designações dos símbolos verbais. A compreensão da linguagem escrita é efetuada, primeiramente, através da linguagem falada; no entanto, gradualmente essa via é reduzida, abreviada, e a linguagem falada desaparece como elo intermediário. A julgar pelas evidências disponíveis, a linguagem escrita adquire o caráter de simbolismo direto, passando a ser percebida da mesma maneira que a linguagem falada. (VYGOSTY, 1984, p. 131-132).
\end{abstract}

Evidenciada a importância da compreensão da língua escrita por meio da língua falada, seja como um sistema de representação ou como instrumento de apoio à memória, problematiza-se qual seria o "ponto de virada" no processo de desenvolvimento da escrita por crianças surdas na apropriação da língua portuguesa escrita, uma vez que para elas a aprendizagem não depende do desenvolvimento da fala. No caso das pessoas surdas, ressalta-se que as especificidades não estão relacionadas somente ao desenvolvimento da fala, mas também à falta ou impossibilidade de acesso à língua falada (aos sons). Além disso, considera-se que os surdos são usuários de outra língua, que não é nem oral e nem auditiva, classificada como uma modalidade diferente daquela usada pelas pessoas ouvintes.

Entretanto, nos dados produzidos nessa investigação, verificou-se que há um período em que a criança surda começa a perceber que a escrita registra um determinado objeto denotado, porém, ela ainda não compreende a lógica do mecanismo da escrita alfabética, diferentemente da criança que começa a estabelecer uma relação entre os sons e as palavras. Demonstrou-se que a criança percebe, ou supõe, que há uma lógica para se escrever, mas ela não sabe qual é e se mostra insegura ao realizar os seus registros, conforme constatado nas entrevistas com a maioria das crianças. Importante ressaltar que, mesmo diante desse contexto, elas começaram a utilizar estratégias que apontaram pistas visuais da escrita; por exemplo, quando um dos colaboradores já sabia registrar alguns nomes de animais, mas tinha dúvidas em como se escrevia outros, registrando LEIO para "leão", JOUOVOPO para "jacaré”, MACOCOCA para “macaco" e UREO para "urso". Nessas situações, é possível dizer que a colaboradora utilizou as pistas visuais da grafia das palavras, sendo que suas tentativas não estão relacionadas à hipótese silábica, pelo fato de não usar a rota auditiva, mas sim à visualidade das palavras. 0 uso de palavras que já conhecem, que contêm letras em comum com o objeto a ser denotado e/ ou o registro de pseudopalavras (PEREIRA, 2015) são algumas das pistas visuais utilizadas pelos colaboradores desta pesquisa.

Considera-se que esse seja um ponto importante do desenvolvimento da escrita dos sujeitos surdos, sendo uma das hipóteses a de que as crianças começam a perceber as pistas visuais da grafia da palavra e, então, passam a copiar as palavras, fazem conjecturas e tentativas de escrita por meio de atividades mentais que podem estar relacionadas à consciência visual (OLIVEIRA, 2009). 0 conceito de consciência visual, proposto por Oliveira (2009), busca estabelecer uma relação entre a ideia veiculada e o registro grafado, pois, ao apropriar-se das imagens visuais, as crianças constroem o conhecimento a partir 
da representação interna em língua de sinais e, posteriormente, na escrita, utilizando a base alfabética. Desse modo, a consciência visual pode ser entendida como um mecanismo que visa a: “[...] representação visual do objeto - a imagem; abstração do objeto como unidade constituída de partes, resultando na representação simbólica do objeto, através da língua de sinais e posterior escrita alfabética” (OLIVEIRA, 2009, p. 196).

Nas produções textuais das crianças envolvendo o gênero carta, verificou-se que alguns desses registros foram realizados de maneira muito distinta da forma como escreveram as palavras na atividade com vocabulário. Evidenciou-se que, no pressuposto presenciado nas produções das crianças B, D e E, o texto se apresenta como algo distinto, maior e mais complexo, como um emaranhado de letras juntas, sem separação. Na produção textual da criança $\mathrm{F}$, constatou-se que a colaboradora fez o uso da escrita para registrar as ideias e os conceitos, contudo, ainda haviam características do texto surdo; ou seja, o texto foi escrito utilizando uma estrutura sintática da Libras, com omissão de artigos e preposições, uso inadequado ou ausência de conectivos da língua portuguesa e não da Libras, dentre outros, conforme apresentado por Brochado (2003).

Entretanto, surgiu um fato novo, que foi o registro em SignWriting ${ }^{4}$ pela colaboradora $F$, indicando que essa forma de registro é mais fácil para ela, relacionando-o à Libras como língua que proporciona sentido às coisas. Silva (2008) constatou em sua pesquisa que a tentativa de representação gráfica de sinais que compõem a Libras pode ser vista como uma manifestação criativa e sofisticada das funções psicológicas superiores das crianças surdas, tendo em vista que o registro gráfico de sinais, visualmente captados por essas crianças na língua de sinais, caracteriza-se como a representação do ritmo sonoro, evidenciado pela criança ouvinte no seu processo de apropriação da escrita.

$\mathrm{Na}$ educação de surdos, na perspectiva da língua em uso, no ensino da língua como conhecimento e produção, de acordo com Lebedeff (2010) a surdez existe e envolve o uso de uma língua que é visual e espacial e, sendo assim, necessita de uma proposta pedagógica pensada para as singularidades linguísticas e culturais que não seja uma mera adaptação de práticas para ouvintes, mas práticas que envolvem o letramento visual para a aprendizagem de uma segunda língua e de uma outra modalidade linguística. Para Machado (2000), a imagem é um sistema simbólico importante no processo de compreensão léxico-semântico da língua escrita pelas pessoas surdas, mas ressalta-se a necessidade da compreensão das relações que a criança estabelece entre texto e imagem. Lembrando que, de acordo com Dondis (2015), o modo visual constitui um corpo de dados que pode ser usado para compor e compreender mensagens para várias finalidades, em vários níveis.

As estratégias e conjecturas que as crianças fazem sozinhas para escrever são importantes, porém, diferentemente da aquisição da língua de sinais - que acontece naturalmente no contato com seus pares -, a escrita só é aprendida através do ensino sistemático e, culturalmente, por mediação (LURIA 1988; VYGOTSKY, 1984). Nas atividades que envolvem o letramento visual, na esteira de Dondis (2015), Taveira (2014) e Lebedeff (2017), a percepção da representação visual da imagem não deve ser entendida como uma

4- De acordo com Stumpf (2004), o sistema SignWriting, de escrita de sinais, representa unidades gestuais, e não unidades semânticas, por isso pode ser aplicado a qualquer língua de sinais dos surdos. 
capacidade inata dos sujeitos, independentemente se são surdos ou ouvintes e, portanto, na realização de um trabalho pedagógico, a experiência visual não deve fazer parte apenas de intuições das práticas docentes. Há a necessidade de organizar o trabalho envolvendo o letramento visual para uma maior compreensão das informações e experiências pelos sujeitos, proporcionado habilidades para que possam ler as imagens e ter um maior refinamento da leitura. Diante do exposto, a mediação do professor se torna fundamental.

Além de estratégias diferenciadas que contemplam a visualidade das crianças surdas, Gesueli (1998) já apontava a importância do processo de construção da narrativa para que a criança surda aprenda a fazer uso da linguagem, assumindo papéis ativos na interlocução, principalmente pelo fato de a maioria ser oriunda de família de ouvintes, não possuindo um contexto linguístico favorável para que isso aconteça no ambiente familiar.

Desta forma, reflete-se sobre as possibilidades de ações que podem contribuir para o "ponto de virada" na apropriação da escrita pelas crianças surdas. Inicialmente, considerase importante conceber que a alfabetização e o letramento dessas crianças se constituem em bases diferentes daquelas utilizadas no ensino da língua escrita pelas crianças ouvintes. Essas diferenças devem ser relacionadas a experiências fundamentadas em pressupostos bilingues e visuais, impondo a necessidade de utilização de estratégias que problematizem a seguinte questão: como um surdo pode compreender o sistema de escrita sem construir a consciência fonológica pela via auditiva?

Caso seja utilizado o mesmo aparato conceitual dos ouvintes na alfabetização e letramento de surdos - coisas com as quais já se está acostumado no ensino das demais crianças -, ocorrerá a comparação da apropriação da escrita das crianças surdas e das ouvintes e certamente haverá uma distorção da realidade. Nessa perspectiva, é pertinente haver uma “ex-posição" (LARROSA, 2015), deixando para trás pressupostos e práticas de escrita que balizaram e continuam balizando as produções textuais dos surdos e, de acordo com Veiga-Neto e Lopes (2010), pensar de outro modo a alfabetização e letramento de surdos, pensando fora do que é dado e já foi pensado, no sentido de não assumir as bases sobre as quais se assenta esse dado que já foi pensado e, dessa maneira, deixar o já pensado para trás.

Neste contexto, diante dos resultados dessa investigação, aponta-se para a alfabetização e o letramento bilíngue como uma hipótese para contribuir com o "ponto de virada" da criança surda. O letramento bilíngue é entendido como um conjunto de práticas pedagógicas que envolvam especificidades da Libras e da língua portuguesa no processo de apropriação da escrita, tais como:

- Escrita de sinais: esta hipótese tem como base os dados coletados na entrevista da colaboradora F. Ao utilizar a escrita de sinais, a criança relacionou os registros à língua de sinais, produzindo significado e atestando que os sinais da Libras poderiam ser registrados na sua língua, na mesma perspectiva encontrada na pesquisa de Lima, Alves e Stumpf (2018), podendo contribuir para a aquisição de novos mecanismos para a abstração na apropriação da língua escrita.

- Escrita diferida: a hipótese de escrita diferida tem como fundamentação o conceito de textualidade diferida (PELUSO, 2014, 2018), que contempla a utilização de recursos 
em vídeo e produção de narrativas sinalizadas, como a contação de história em Libras e os vídeos de cada criança, registrados com um smartphone, nesta pesquisa, ao final de cada entrevista. Essas produções em vídeo funcionam como um texto diferido, possuindo estrutura e função similar ao texto escrito. Os vídeos produzidos em Libras podem ser entendidos como a "fala" dos surdos tornada visível, conforme apontou Soares (2016) em relação à apropriação da língua escrita pela criança ouvinte.

- Escrita bilíngue: esta hipótese envolve os aspectos interlinguísticos e intermodais da escrita da pessoa surda, assim como se constatou no texto em língua portuguesa escrito pela colaboradora F. Essa produção textual é composta com a estrutura linguística da língua de sinais, cujas especificidades são comuns em textos realizados em português por pessoas surdas (BROCHAD0, 2003), em uma perspectiva de segunda língua (SOUZA et al., 2016).

Neste sentido, a ação inicial que deve ser considerada é a problematização sobre qual é o objeto a ser ensinado e o que se está ensinando quando se ensina a língua portuguesa escrita para pessoas surdas. Para Soares (2016, p. 25, grifo do autor), “[...] os métodos de alfabetização têm sido sempre a questão porque derivam de concepções diferentes sobre o objeto da alfabetização, isto é, sobre $o$ que se ensina quando se ensina a língua escrita". No caso da educação de surdos, o ensino da língua portuguesa escrita está relacionado à escrita de uma segunda língua e, também, à aprendizagem de um sistema de escrita que representa a língua falada oralmente, a qual a pessoa surda não tem ou tem pouco acesso.

Portanto, os resultados desta investigação, em sintonia com Larrosa (2015), abrem a possibilidade de romper com o que foi posto e não é mais admitido, abrindo espaços e perguntas para novos modos de pensamento na educação de surdos em direção a novas pesquisas que poderiam aprofundar - caracterizando e questionando - o "ponto de virada" na apropriação da língua portuguesa escrita pelas crianças surdas.

\section{Referências}

BROCHADO, Sônia Maria Dechandt. A apropriação da escrita por crianças surdas usuárias da língua de sinais brasileira. 2003. Tese (Doutorado em Letras) - Faculdade de Ciências e Letras de Assis, Universidade Estadual Paulista, Assis, 2003.

CAPOVILLA, Alessandra Gotuzo Seabra. Leitura, escrita e consciência fonológica: desenvolvimento, intercorrelações e intervenções. 2000. Tese (Doutorado em Psicologia) - Instituto de Psicologia, Universidade de São Paulo, São Paulo, 2000.

CARDOSO, Silvia Helena Barbi. A questão da referência: das teorias clássicas à dispersão de discursos. Campinas: Autores Associados, 2003.

CORREA, Bianca Cristina; BUCCI, Lorenzza. A vivência em uma pré-escola e as expectativas quanto ao ensino fundamental sob a ótica das crianças. Jornal de Políticas Educacionais, Curitiba, v. 12, n. 9, p. 1-20, 2018.

CRUZ, Rosimeire Costa de Andrade. A pré-escola vista pelas crianças. In: REUNIÃO NACIONAL DA ANPED, 32., 2009, Caxambu. Anais [...]. Rio de Janeiro: Anped, 2009. Disponível em: http://www.anped.org.br/ sites/default/files/gt07-5619-int.pdf. Acesso em: 20 jun. 2017. 
DONDIS, Donis A. Sintaxe da linguagem visual. Tradução Jefferson Luiz Camargo. 3. ed. São Paulo: Martins Fontes, 2015.

FARACO, Carlos Alberto. Linguagem escrita e alfabetização. São Paulo: Contexto, 2012.

FAVORETO DA SILVA, Rosane Aparecida. Experiências de crianças surdas com a palavra escrita. 2020. Tese (Doutorado em Educação) - Faculdade de Educação, Universidade de São Paulo, São Paulo, 2020.

FERREIRO, Emilia; TEBEROSKY, Ana. Psicogênese da língua escrita. Porto Alegre: Artmed, 1999.

FERREIRO, Emilia. Cultura escrita e educação. Porto Alegre: Artmed, 2001.

FIGUEIRED0, Luciana Cabral; GUARINELLO, Ana Cristina. Literatura infantil e a multimodalidade no contexto de surdez: uma proposta de atuação. Revista Educação Especial, Santa Maria, v. 26, n. 45, p. 175-193, 2013.

FORMAGI0, Carolina Lima Silva; LACERDA, Cristina Broglia Feitosa de. Práticas pedagógicas do ensino de português como segunda língua para alunos surdos no ensino fundamental. In: LACERDA, Cristina Broglia Feitosa de; SANTOS, Lara Ferreira dos; MARTINS, Vanessa Regina de Oliveira (org.). Escola e diferença: caminhos para a educação bilíngue de surdos. São Carlos: UFSCar, 2016. p. 169-241.

GESUELI, Zilda Maria. A criança surda e o conhecimento construído na interlocução em língua de sinais. 1998. Tese (Doutorado em Educação) - Universidade Estadual de Campinas, Campinas, 1998.

GESUELI, Zilda Maria. A escrita como fenômeno visual nas práticas discursivas de alunos surdos. In: LODI, Ana Claudia Balieiro; MELO, Ana Dorziat Barbosa de; FERNANDES, Eulalia (org.). Letramento, bilinguismo e educação de surdos. 2. ed. Porto Alegre: Mediação, 2015. p. 173-186.

GESUELI, Zilda Maria; MOURA, Lia de. Letramento e surdez: a visualização das palavras. ETD: Educação Temática Digital, Campinas, v. 7, n. 2, p. 110-122, 2006.

KARNOPP, Lodenir Becker; PEREIRA, Maria Cristina da Cunha. Concepções de leitura e de escrita e educação de surdos. In: LODI, Ana Claudia Balieiro; MELO, Ana Dorziat Barbosa de; FERNANDES, Eulalia (org.). Letramento, bilinguismo e educação de surdos. 2. ed. Porto Alegre: Mediação, 2015. p. 125-134.

KRAMER, Sonia. Autoria e autorização: questões éticas na pesquisa com crianças. Cadernos de Pesquisa, São Paulo, n. 116, p. 41-59, 2002.

LANKSHEAR, Colin; KNOBEL, Michele. Pesquisa pedagógica: do projeto à implementação. Tradução Magda França Lopes. Porto Alegre: Artmed, 2008.

LAROSSA, Jorge. Tremores: escritos sobre experiência. Tradução Cristina Antunes e João Wanderley Geraldi. Belo Horizonte: Autêntica, 2015.

LEBEDEFF, Tatiana Bolívar. Aprendendo a ler "com outros olhos": relatos de oficinas de letramento visual com professores surdos. Cadernos de Educação, Pelotas, n. 36, p. 175-195, 2010. 
LEBEDEFF, Tatiana Bolívar. 0 povo do olho: uma discussão sobre a experiência visual e surdez. In: LEBEDEFF, Tatiana Bolívar (org.). Letramento visual e surdez. Rio de Janeiro: Wak, 2017. p. 226-251.

LIMA, Marleide Francisco de; ALVES, Edneia de Oliveira; STUMPF, Marianne Rossi. Escrita de sinais: uma proposta para o letramento de surdos em L1. Revista Prática Docente, Confresa, v. 3, n. 1, p. 140-157, 2018.

LURIA, Alexander Romanovich. 0 desenvolvimento da escrita na criança. In: VIGOTSKII, Lev Semenovich; LURIA, Alexander Romanovich; LEONTIEV, Alex N. (Org.). Linguagem, desenvolvimento e aprendizagem. Tradução Maria da Penha Villalobos. São Paulo: Ícone: USP, 1988. p. 143-189.

MACHADO, Edna de Lourdes. Psicogênese da leitura e da escrita na criança surda. 2000. Tese (Doutorado em Psicologia da Educação) - Pontifícia Universidade Católica de São Paulo, São Paulo, 2000.

MORAIS, Artur Gomes de. Sistema de escrita alfabética. São Paulo: Melhoramentos, 2012.

OLIVEIRA, Marta Kohl de. Pensar a educação: contribuições de Vygotsky. In: CASTORINA, José Antonio et al. Piaget-Vygostky: novas contribuições para o debate. Tradução Claudia Schilling. 6. ed. São Paulo: Ática, 2000. p. 51-83.

OLIVEIRA, Thereza Cristina Bastos Costa de. A escrita do aluno surdo: interface entre a libras e a língua portuguesa. 2009. Tese (Doutorado em Educação) - Faculdade de Educação, Universidade Federal da Bahia, Salvador, 2009.

PELUSO, Leonardo. Los sordos, sus lenguas y su textualidad diferida. Traslaciones, Mendoza, v. 5, n. 9, p. 40-61, 2018.

PELUSO, Leonardo. Textualidad diferida y videograbaciones en LSU: un caso de política linguística. Revista Digital de Políticas Lingüísticas, Córdoba, v. 6, n. 6, p. 16-37, 2014.

PEREIRA, Maria Cristina da Cunha. Reflexões sobre a aquisição da escrita da língua portuguesa por criança surda usuária da língua brasileira de sinais. Revista Espaço, Rio de Janeiro, n. 43, p. 239-263, 2015.

R0J0, Roxane. Letramentos múltiplos, escola e inclusão social. São Paulo: Parábola, 2009.

SANTAELLA, Lucia. Leitura de imagens. São Paulo: Melhoramentos, 2012.

SILVA, Tânia dos Santos Alvarez da. A aquisição da escrita pela criança surda desde a educação infantil. 2008. Tese (Doutorado em Educação) - Universidade Federal do Paraná, Curitiba, 2008.

SOARES, Magda. Alfabetização: a questão dos métodos. São Paulo: Contexto, 2016.

SOARES, Magda. Letramento: um tema em três gêneros. 3. ed. Belo Horizonte: Autêntica, 2014.

SOUZA, Regina Maria de et al. Relatório do grupo de trabalho para analisar e propor a implantação da estrutura adequada para atender ensino de Libras e demais questões correlatas. In: LINS, Heloísa Andreia 
de Matos; SOUZA, Regina Maria de; NASCIMENTO, Lilian Cristine Ribeiro do (org.). Plano nacional de educação e as políticas locais para implantação da educação bilíngue para surdos. Campinas: Unicamp, 2016. p. 1-28.

STREET, Brian V. Os novos estudos sobre o letramento: histórico e perspectivas. In: MARINHO, Marildes; CARVALHO, Gilcinei Teodoro (org.). Cultura escrita e letramento. Belo Horizonte: UFMG, 2010. p. 33-53.

STUMPF, Marianne Rossi. Sistema signwriting: por uma escrita funcional para o surdo. In: THOMA, Adriana da Silva; LOPES, Maura Corcini (org.). A invenção da surdez: cultura, alteridade, identidade e diferença no campo da educação. Santa Cruz do Sul: Unisc, 2004. p. 143-159.

TAVEIRA, Cristiane Correia. Por uma didática da invenção surda: prática pedagógica nas escolas-piloto de educação bilíngue no município do Rio de Janeiro. 2014. Tese (Doutorado em Educação) - Pontifícia Universidade Católica do Rio de Janeiro, Rio de Janeiro, 2014.

VEIGA-NETO, Alfredo; LOPES, Maura Corcini. Para pensar de outros modos a modernidade pedagógica. ETD: Educação Temática Digital, Campinas, v. 12, n. 1, p. 147-166, 2010.

VYGOTSKY, Lev Semenovich. A formação social da mente. Tradução José Cipolla Neto, Luis Silveira Menna Barreto e Solange Castro Afeche. São Paulo: Martins Fontes, 1984.

Recebido em: 04.06.2020

Aprovado em: 05.08.2020

Rosane Aparecida Favoreto da Silva é doutora em educação pela Faculdade de Educação da Universidade de São Paulo (FEUSP), mestra em educação pela Universidade Federal do Paraná (UFPR), graduada em letras com habilitação em língua brasileira de sinais (UFSC) e professora da área da educação de surdos pela Secretaria de Estado da Educação do Paraná (SEED-PR).

Alessandra Gotuzo Seabra é psicóloga, com mestrado, doutorado e pós-doutorado em psicologia experimental pela Universidade de São Paulo (USP), professora do Programa de Pós-graduação em Distúrbios do Desenvolvimento da Universidade Presbiteriana Mackenzie (UPM) e bolsista de produtividade 1B do Conselho Nacional de Desenvolvimento Científico e Tecnológico (CNPq). 